Clinical Study

\title{
Long-Term Follow-up of a Randomized Study of Oral Etoposide versus Viscum album Fermentatum Pini as Maintenance Therapy in Osteosarcoma Patients in Complete Surgical Remission after Second Relapse
}

\author{
Alessandra Longhi $\mathbb{D}^{1},{ }^{1}$ Marilena Cesari, ${ }^{1}$ Massimo Serra, ${ }^{2}$ and Erminia Mariani $\mathbb{D}^{3}$ \\ ${ }^{1}$ Chemotherapy Division, IRCCS Istituto Ortopedico Rizzoli, Bologna, Italy \\ ${ }^{2}$ Laboratory of Experimental Oncology, IRCCS Istituto Ortopedico Rizzoli, Bologna, Italy \\ ${ }^{3}$ Immunoreumathology and Tissue Regeneration Laboratory, IRCCS Istituto Ortopedico Rizzoli, \\ Bologna, Italy
}

Correspondence should be addressed to Alessandra Longhi; alessandra.longhi@ior.it

Received 26 January 2020; Accepted 20 March 2020; Published 27 April 2020

Academic Editor: Manish Agarwal

Copyright (c) 2020 Alessandra Longhi et al. This is an open access article distributed under the Creative Commons Attribution License, which permits unrestricted use, distribution, and reproduction in any medium, provided the original work is properly cited.

\begin{abstract}
Background. In relapsed osteosarcoma, the 5-yr postrelapse disease-free survival (PRDFS) rate after the second relapse is $<20 \%$. In June 2007, a randomized study was started comparing oral etoposide vs Viscum album fermentatum Pini (an extract derived from the parasitic plant Viscum album L., European mistletoe) as maintenance therapy in patients with metastatic osteosarcoma in complete surgical remission after the second relapse. The primary endpoint was the PRDFS rate at 12 months (compared to the historical control rate). This is a long-term updated result. Patients and Methods. 10 patients received oral etoposide $50 \mathrm{mg} / \mathrm{m}^{2}$ daily for 21 days every 28 days for 6 months, and 9 patients received Viscum album fermentatum Pini 3 times/wk subcutaneously for 1 year. The study closed early in July 2011 due to insufficient recruitment. Lymphocyte subpopulations were analyzed at T0, T3, T6, T9, and T12 months. Results. On 30 June 2019, at a median follow-up ITT of 83 months (range 3-144 ms), a median PRDFS of $106 \mathrm{~ms}$ (2-144) was observed in the Viscum arm with 5/9 patients who never relapse vs a PRDFS of 7 months (3-134) in the etoposide arm (all patients in the Etoposide arm relapsed) (hazard ratio HR=0.287, 95\% CI: 0.076-0.884, $p=0.03$ ). Model forecast 10 -yr overall survival rates as $64 \%$ in the Viscum arm and 33\% in the etoposide arm. Lymphocyte subpopulation counts (CD3, CD4, and CD56) showed an increase in the Viscum arm while a decrease was observed in the etoposide arm during treatment. Conclusions. After 12 years from the start of the trial, the patients in the Viscum arm continue to show a considerably longer PRDFS compared to oral etoposide, and a trend for an advantage in OS is evident even if the number of treated patients is too small to draw conclusions. Viscum as maintenance treatment after complete surgical remission in relapsed osteosarcoma should be further investigated and compared with other drugs.
\end{abstract}

\section{Introduction}

Overall survival of patients with relapsed osteosarcoma remained unsatisfactory and unchanged over the last three decades, as well as the efforts to develop novel active agents have generally yielded disappointing results [1,2]. Main prognostic factors for the survival of relapsed patients include the location of relapse (better prognosis for the lung vs bone), the time to progression ( $>24$ months vs shorter periods), and the number of lung metastases (1-3 vs more than 3 nodules) [3]. Relapse mainly affects the lungs, and patients achieving complete surgical remission after relapse have a prolonged 5-year postrelapse survival [1]. Subsequent repeated relapses decrease further the chance of cure. In our previous study, 235 relapsed osteosarcoma patients had a 5yr PRDFS of $29 \%$, and only 14 out of $120(11.6 \%)$ patients 
who had a second relapse never relapsed for the third time [1]. The COSS study published in 2009 on 249 osteosarcoma patients after a second relapse showed that the five-year overall and event-free survival rates were $16 \%$ and $9 \%$, respectively [2]. A more recent paper (2017) [4] on 60 Italian patients with relapsed osteosarcoma followed from 2003 to 2013 showed that the median postrelapse disease-free survival (PRDFS) after the second relapse was 6 months (range 42 days to 44 months). The majority of patients (84\%) relapsed less than 12 months after the second complete surgical remission. The 5-year postsecond relapse survival rate was $22 \%$. Lung recurrence as a unique site correlated with a better 5 -year survival $(33.6 \%)$ compared to other sites of recurrence $(5 \% ; p=0.008)$ [4]. Patients who relapse with operable metastases are usually operated. Postoperative adjuvant chemotherapy is usually not a standard after relapse because there is no evidence of an advantage that would outweigh the chemotherapeutic toxicity, and most effective drugs are employed in the adjuvant phase. Chemotherapy in a relapsed patient is usually administered in advanced or inoperable diseases. Tumors have immunosuppressive capacities through secretion of various cytokines favoring an escape from the immune response [5]. Therapeutic strategies to counteract the tumor-induced immunosuppressive effect are employed by blocking immune checkpoints (CTLA-4, PD-L1, or PD-1) on T cells with specific antibodies and thereby restoring the cytotoxic capacity of these cells [6]. Immunotherapy in bone sarcoma was first applied by Coley who injected a mixture of streptococcal bacteria into unresectable bone sarcomas in 1891, achieving an immunological reaction and tumor regression [7]. Few studies are available on immunotherapies in osteosarcoma with limited results [8]. Interferon proved to be unsatisfactory in improving the overall survival in adjuvant setting in localized osteosarcoma in the EURAMOS 1 trial [9]. Muramyl tripeptide (MTP), a BCG-derived drug, which activates macrophages, administrated together with ifosfamide, improved 6 years of OS from $70 \%$ to $78 \%(p=0.03)$ in patients with localized osteosarcoma in adjuvant setting [10]. MTP has been licensed in European countries for the adjuvant treatment of localized osteosarcoma.

Immunotherapy with anti-PD-L1 showed promising cure advantages in some cancers other than osteosarcoma. Less than $20 \%$ of osteosarcoma patients are PD-L1 positive. A recent report of pembrolizumab (an anti-PD-L1) employed in a 12 advanced osteosarcoma patients series produced unsatisfactory results [11].

Viscum album extracts (European mistletoe) is part of integrative medicine, and its usage is popular among cancer patients in German-speaking countries [12,13]. Viscum album extracts contain a variety of immunoactive compounds that include lectins, viscotoxins, oligosaccharides and polysaccharides, flavonoids, and triterpene acids [14]. The antitumor activity of Viscum lectins has been demonstrated both in in vitro and in vivo, and it has been supposed to be related to the activation of monocytes/macrophages, granulocytes, natural killer cells, Tcells, and dendritic cells and to the induction of a variety of cytokines [5]. Furthermore,
Viscum album extracts appear to interfere with tumor angiogenesis [15].

Recently, xenograft models showed the activity of a Viscum extract in osteosarcoma [16] and in Ewing sarcoma both in in vitro and in vivo conditions [17]. In analogy to previous studies on other tumors, it was shown that Viscum extracts have proapoptotic activity on osteosarcoma cells, via caspase activation, and also it displayed a synergistic activity with chemotherapeutic drugs usually employed in osteosarcoma therapy (doxorubicin, ifosfamide, and etoposide) [16]. A further preclinical study demonstrated the cytotoxic activity of Viscum Species in different pediatric cancer cells [18].

Other in vitro studies demonstrated different activation of dendritic cells and promotion of Th1 immune response according to different species of Viscum [19].

Some therapeutic protocols for osteosarcoma employed etoposide (topoisomerase II inhibitor) mainly IV in combination with ifosfamide at relapse. Yet, oral administration is used as well, and in clinical practice, usually in recurrent disease. A recent report [20] on 28 metastatic osteosarcoma patients showed that the use of etoposide $25 \mathrm{mg}$ t.i.d induced $15 \%$ partial remission. The median PFS was 3.7 months, and the median overall survival was 7.4 months.

Hematologic toxicity is one of the main limiting characteristics of etoposide with an increased risk of secondary malignancy either after IV [21] or after oral administration [22-24].

In a previous paper [23], we presented the results of a randomized study of a Viscum album extract or oral etoposide administration in osteosarcoma patients in complete surgical remission after second relapse. In which, PRDFS rates, quality of life, and tolerability of each therapy after 12 months of treatment were reported [25].

In the present paper, we report updated results on PRDFS and on overall survival (OS) of those study population after a follow-up period of 12 years from the opening of the study.

\section{Materials and Methods}

This monoinstitutional, prospective, randomized, open-label study approved by the Ethic Committee of the Istituto Ortopedico Rizzoli (IOR), Bologna, was registered in the in the EU clinical trials register (EudraCT number 2006002676-18) and conducted according to the Declaration of Helsinki. Patients in complete surgical remission after the second relapse for osteosarcoma were enrolled starting in June 2007, and 18 out of 20 patients had lung metastasectomy for their second relapse; lung metastases were 1-3 nodule each and were all resected in our institute from the same team of surgeon, and margins were considered wide if occurred in normal lung tissue. Two patients had bone metastases, and their margins were wide.

Study characteristics are presented in summarized form only. For a detailed description of the whole study and of patients' inclusion criteria, sample size, and patients' randomization see Longhi et al. [25]. 
2.1. Treatment. Etoposide was administered orally in doses of $50 \mathrm{mg} / \mathrm{m} 2$ per day for 21 days every 28 days for 6 cycles. Viscum album fermentatum Pini (manufactured as "Iscador P" by Iscador AG, Switzerland) was administered subcutaneously 3 times a week for 12 months. The Viscum album extract was injected subcutaneously (abdominal) 3 times/ week. The starting dose was 2 boxes of Series 0 for 14 vials (each box contains 2 vials of $0.01 \mathrm{mg}, 2$ vials of $0.1 \mathrm{mg}$, and 3 vials of $1 \mathrm{mg}$ ), followed by 2 boxes of series I for 14 vials ( 2 vials of $0.1 \mathrm{mg}, 2$ vials of $1 \mathrm{mg}$, and 3 vials of $10 \mathrm{mg}$ ) vials, and subsequent treatment with series II (1, 10, and $20 \mathrm{mg}$ ) was carried out continuously until the $12^{\text {th }}$ month [25].

2.2. Clinical Assessment. Clinical and radiological assessment was done at the screening visit and after 3, 6, 9, and 12 months [25] of treatment, and then if no progression was registered, it was done every 4 months until 3 years, then every six months until the $5^{\text {th }}$ year, and then every year for at least until the tenth year. All patients were also planned to undergo blood test for the evaluation of lymphocyte subpopulations at T0, T3, T6, T9, and T12 months. Phenotype characterization of the different lymphocyte subpopulations was performed by specific monoclonal antibodies (CD3 $=$ panT, CD4 = helper, CD8 = suppressor, CD56 and CD16=natural killer, and CD19= panB).

2.3. Statistical Methods. For the long-term evaluation presented here, PRDFS and OS have been statistically compared between treatment arms using the log-rank test. Hazard rates and 95\% confidence intervals (CI) have been derived from a corresponding Cox proportional hazard regression with the treatment arm as the only independent factor. Forecasts of 10-year OS rates have been estimated using parametric proportional hazard regression models with lognormal, exponential, log-logistic, or Weibull distribution of the survival times (Klein and Moeschberger, 1997). The lognormal model fitted the data best (smallest value for $-2 * \log$-likelihood); therefore, these estimates are shown. Due to the decrease in sample size from 18 to 10 per study arm, no other adjustments were done, especially the global alpha error level of 5\% remained unchanged in order to not violate the validity of the statistical testing procedure and its interpretation. Due to the decrease in sample size from 18 to 10 per study arm, the power of the single-arm binomial test for superiority of a given treatment over the historical PRDFS rate of $12 \%$ dropped from $81 \%$ to $61.8 \%$. However, once a statistically significant difference (here, the superiority of $55.6 \%$ PRDFS rate of the Viscum arm at 1 yr over the historical $12 \%$ rate) has been found, the power of the (planned) test becomes irrelevant (i.e., statistically significant difference is valid independent on sample size). With regard to etoposide, the 1-yr PRDFS was $27.3 \%$ compared with the expected rate of $35 \%$ which is not statistically significant. Anyway, the long-term follow-up revealed a PRDF totally significant for Viscum over the etoposide arm.

\section{Results}

From June 2007 to July 2011, twenty patients were randomized. Eleven patients were randomly assigned to the etoposide arm and nine to the Viscum arm. One patient enrolled in the etoposide arm refused to accept etoposide after randomization, and he has withdrawn from the trial; he was analyzed as assigned to etoposide following the intention-to-treat approach.

Due to inadequate recruitment compared to what it was planned (36 patients in three years, 18 each arm), the study was terminated early after 48 months by protocol amendment after the inclusion of 20 patients (11 etoposide and 9 Viscum). Data updated in July 2013 were already published [25]. Patients were continued to be followed periodically. The analysis presented here has been updated on June 30, 2019, 12 years after the start of the study and at a median follow-up of 106 months (range 3-144) of 19 treated patients or 83 months (3-144) considering intention-to-treat (ITT) analysis on 20 randomized patients. Males were 11 and females 9; mean age at baseline was 33.9 years (range 11-65). Arms were well balanced for risk factors such as site of relapse, number of lesions at the second relapse and intervals from the end of chemotherapy and the first and second relapse, and percentage of necrosis of primary tumor (necrosis $>90 \%=$ good responders; necrosis $\leq 90 \%=$ poor responder) (Table 1). ABCB1 P-glycoprotein positivity was also evaluated on a metastatic specimen resected previously to treatment as a negative prognostic factor in osteosarcoma [26]. ABCB1 positivity was revealed in metastatic tissue in 2 out of 4 patients in the Viscum arm (the other 2 were PgP negative) and in 1 out of 4 patients in the etoposide arm. The oneyear PRDFS and OS were already reported: only the 1-year PRDFS rate of the Viscum arm differed significantly from the historical $12 \%$ rate $(p=0.004)$ [23]. After the end of study participation, two patients of the Viscum arm continued to use Viscum either for 12 months or at a 6month on/off schedule, respectively. One patient of the etoposide arm after resection of lung metastases as the third relapse crossed over to Viscum and continued for 3 years spontaneously, and he is alive, free from disease. One patient in the etoposide arm after a third relapse of osteosarcoma (lung metastases, resected) developed a second cancer one year after (GIST of stomach) which was resected. The patient is alive and free of both cancer in June 2019. The 5-years PRDFS rate in the Viscum arm was $55.5 \%$ (95\% CI $21-86 \%)$ and $9 \%$ (95\% CI 0, 2-43\%) in the etoposide arm. The 5 -yr OS was $66.7 \%$ (95\% CI: $28.2-87.8$ ) in the Viscum arm vs $40 \%$ (95\% CI: $12.3-67$ ) in the etoposide arm. On 30 June 2019, five out of nine enrolled patients in the Viscum arm never relapsed since the start of protocol, while all patients in the etoposide arm relapsed; the median PRDFS was 106 months (range 2-144) in the Viscum arm versus a median PRDFS of 7 months (range 1-84 months) in the etoposide arm (hazard ratio $\mathrm{HR}=0.287$, 95\% CI: 0.076-0.884, $\chi^{2}=4.714, p=0.0299$ ) (Figure 1).

In the etoposide arm, 4 out of 11 patients were alive and free of disease after a $3^{\text {rd }}$ relapse, median OS 43 months 
TABLe 1: Patients characteristics.

\begin{tabular}{|c|c|c|c|c|c|c|c|c|c|c|c|}
\hline PTS & Start TX & Age & Sex & Arm & Site $/ \mathrm{N}^{\circ}$ & $\begin{array}{c}\mathrm{T} . \\
\text { necrosis }\end{array}$ & $\begin{array}{l}\text { PgP on } \\
\text { Met. }\end{array}$ & PRDFS & $\begin{array}{l}\text { OS } \\
(\mathrm{ms})\end{array}$ & Outcome & $\begin{array}{l}\text { Status } \\
30.6 .19\end{array}$ \\
\hline 1 & $\begin{array}{c}08 / 06 / \\
07\end{array}$ & 48 & $\mathrm{~F}$ & Viscum P & Lung one & NA & $\mathrm{NE}$ & 144 & 144 & NED & NED \\
\hline 2 & $\begin{array}{c}03 / 09 / \\
07\end{array}$ & 18 & $\mathrm{~F}$ & Viscum P & Lung two & PR & Pos & 134 & 134 & NED & NED \\
\hline 3 & $\begin{array}{c}02 / 10 / \\
07\end{array}$ & 28 & $\mathrm{M}$ & Viscum P & Lung two & GR & Pos & 140 & 140 & NED & NED \\
\hline 4 & $\begin{array}{c}21 / 04 / \\
08\end{array}$ & 29 & $\mathrm{M}$ & Viscum P & Lung one & GR & NA & 3 & 17 & $\mathrm{R}$ & Dead \\
\hline 5 & $\begin{array}{c}19 / 09 / \\
08\end{array}$ & 30 & $\mathrm{~F}$ & Viscum P & Lung two & $\mathrm{PR}$ & $\mathrm{NE}$ & 121 & 121 & NED & NED \\
\hline 6 & $\begin{array}{c}23 / 09 / \\
08\end{array}$ & 21 & $\mathrm{~F}$ & Viscum $\mathrm{P}$ & $\begin{array}{l}\text { Lung } \\
\text { three }\end{array}$ & PR & $\mathrm{Neg}$ & 6 & 120 & $\mathrm{R}$ & NED1 \\
\hline 7 & $\begin{array}{l}02 / 04 / \\
10\end{array}$ & 20 & $\mathrm{~F}$ & Viscum P & Bone one & PR & $\mathrm{Neg}$ & 106 & 106 & NED & NED \\
\hline 8 & $\begin{array}{c}23 / 07 / \\
10\end{array}$ & 41 & M & Viscum $\mathrm{P}$ & Lung one & GR & $\mathrm{NE}$ & 2 & 24 & $\mathrm{R}$ & Dead \\
\hline 9 & $\begin{array}{c}30 / 06 / \\
11\end{array}$ & 22 & $\mathrm{M}$ & Viscum $\mathrm{P}$ & Lung one & GR & $\mathrm{Neg}$ & 11 & 36 & $\mathrm{R}$ & Dead \\
\hline 10 & $\begin{array}{c}12 / 06 / \\
07\end{array}$ & 28 & $\mathrm{M}$ & Etoposide & Bone one & PR & NA & 3 & 5 & $\mathrm{R}$ & Dead \\
\hline 11 & $\begin{array}{c}17 / 01 / \\
08\end{array}$ & 62 & $\mathrm{~F}$ & Etoposide & Lung one & GR & NA & 12 & 128 & $\mathrm{R}$ & NED 1 \\
\hline 12 & $\begin{array}{c}17 / 01 / \\
08\end{array}$ & 48 & M & Etoposide & Lung one & PR & $\mathrm{NE}$ & 6 & 134 & $\mathrm{R}$ & NED 1 \\
\hline 13 & $\begin{array}{c}17 / 03 / \\
08\end{array}$ & 16 & $\mathrm{~F}$ & Etoposide & Lung one & GR & $\mathrm{Neg}$ & 3 & 5 & $\mathrm{R}$ & Dead \\
\hline 14 & $\begin{array}{c}07 / 01 / \\
09\end{array}$ & 11 & M & Etoposide & Lung two & GR & $\mathrm{Neg}$ & 1 & 3 & $\mathrm{R}$ & Dead \\
\hline 15 & $\begin{array}{c}10 / 07 / \\
09\end{array}$ & 35 & $\mathrm{~F}$ & Etoposide & Lung one & NA & $\mathrm{Neg}$ & 9 & 118 & $\mathrm{R}$ & NED 1 \\
\hline 16 & $\begin{array}{c}28 / 05 / \\
09\end{array}$ & 65 & $\mathrm{M}$ & Etoposide & Lung two & NA & $\mathrm{Neg}$ & 84 & 119 & $\mathrm{R}$ & NED 1 \\
\hline 17 & $\begin{array}{c}11 / 02 / \\
10\end{array}$ & 17 & M & Etoposide & Lung two & $P R$ & Pos & 4 & 25 & $\mathrm{R}$ & Dead \\
\hline 18 & $\begin{array}{c}11 / 05 / \\
10\end{array}$ & 63 & $\mathrm{M}$ & Etoposide & Lung one & NA & Pos & 42 & 60 & $\mathrm{R}$ & Dead \\
\hline 19 & $\begin{array}{c}08 / 07 / \\
11\end{array}$ & 17 & $\mathrm{~F}$ & Etoposide & Lung two & $\mathrm{PR}$ & Neg & 8 & 23 & $\mathrm{R}$ & Dead \\
\hline 20 & $\begin{array}{c}08 / 08 / \\
11\end{array}$ & 67 & M & $\begin{array}{c}\text { Etop never started ITT NA } \\
43\end{array}$ & $\mathrm{NE}$ & Dead & ITT & & & & \\
\hline
\end{tabular}

Site $/ \mathrm{N}^{\circ}=$ site of the $2^{\text {nd }}$ metastase, $\mathrm{N}$ of lesions; tumor necrosis: necrosis on primary tumor; $\mathrm{GR}=$ good responder $>90 \%$ and $\mathrm{PR}=$ poor responder $\leq 90 \%$; $\mathrm{PgP}$ on metastases: pos $=$ Positive, $\mathrm{Neg}=$ Negative; $\mathrm{NA}=$ not available and $\mathrm{NE}=$ not evaluable; $\mathrm{NED}=$ nonevidence of disease after enrollment: NED1 = nonevidence of disease after treatment for a third relapse; $\mathrm{R}$ = relapse; ITT = intention-to-treat; PRDFS: postrelapse disease-free survival; OS: overall survival.

(range 3-134), while 6 out of 9 patients in the Viscum arm were alive with a median OS of 120 months (range 14-144).

A parametric proportional hazard regression model time forecasts 10-year OS rates for the Viscum and etoposide arms of $64 \%$ and $33 \%$, respectively, assuming a lognormal distribution of survival (Figure 2).

On 30 June 2019, the PRDFS of the five long-term survivors in the Viscum arm were 144, 140, 134, 121, and 106 months, respectively.

The count of lymphocyte subpopulations was performed in 7 patients in the Viscum arm (5 of whom had full test until T12 months) and 7 patients in the etoposide arm (4 until T12 months) at T0, T3 ms, T6 ms, T9 ms, and T12 ms, and they showed an increase in $\mathrm{CD} 3, \mathrm{CD} 4$, and $\mathrm{NK}$ after $6 \mathrm{~ms}$ of Viscum therapy, while a net decrease of these lymphocyte subpopulations was observed in the first 3 months of treatment in the etoposide group (Figures 3 and 4). The correlation between changes of each of the three T-lymphocytes subpopulations (CD3, CD4, and NK) demonstrated a consensual modification in the Viscum arm, while on the contrary, they had a disorganized pattern in the etoposide arm (Table 2). Patients after 12 months of study were continued to be followed with simple blood count regularly every visit, not with lymphocyte subpopulation count, and no abnormal changes were reported in total white blood cells or total lymphocytes in the following controls. 


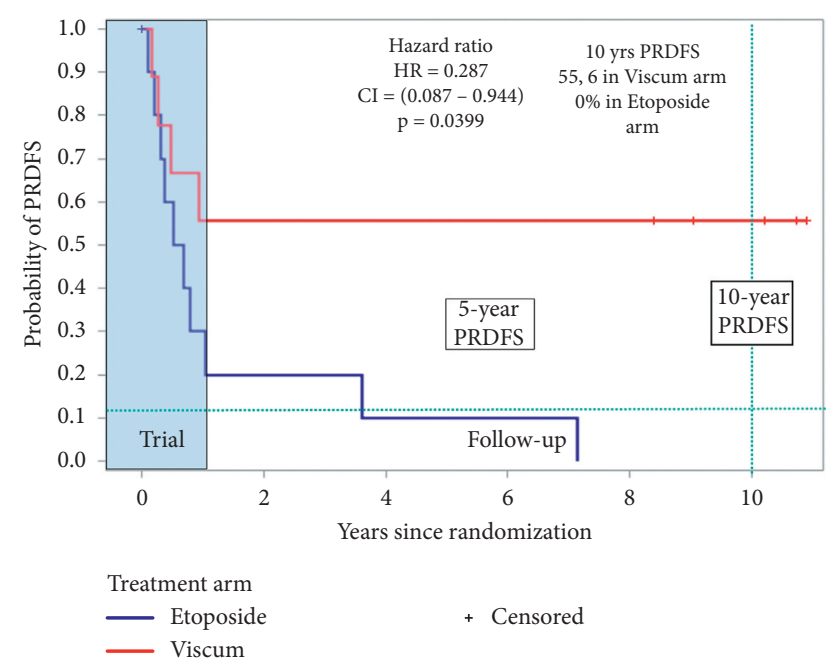

Figure 1: Postrelapse disease-free survival.

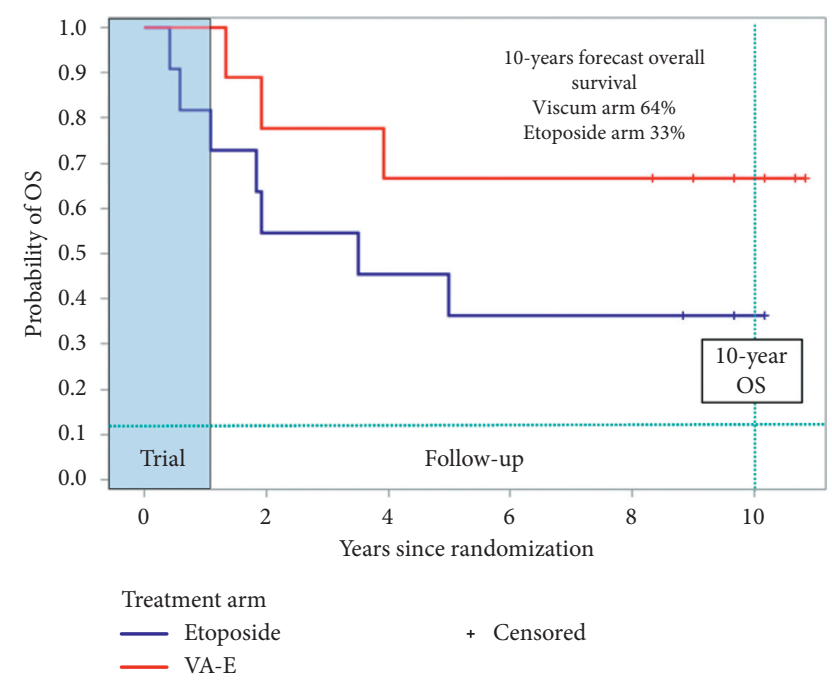

Figure 2: Overall survival.

\section{Discussion}

The treatment of relapsed osteosarcoma patients remains unsatisfactory especially after a second and further relapse, and surgery is the best treatment when feasible and can prolong PRDFS (1,2, and 3). Chemotherapy treatment in absence of measurable disease after complete surgical remission in relapsed patients is usually nonstandard. Few studies were published on maintenance therapy in osteosarcoma. A randomized study on metronomic chemotherapy as maintenance therapy in localized osteosarcoma was published in 2016. 298 patients with localized osteosarcoma were randomized to receive metronomic chemotherapy with oral cyclophosphamide + methotrexate for 73 weeks as maintenance therapy vs no therapy after usual neoadjuvant chemotherapy with MAP: no benefit on disease-free survival or overall survival was reported [27]. It is relevant that $35 \%$ of those patients randomized to receive metronomic chemotherapy refused it.
Viscum album fermentatum has a long history being used for over 80 years as a complementary integrative medicine, and it is safe with limited toxicity; it has been employed in several studies with some benefit reported on survival [28] and QOL, but many of these studies have methodologic flaws. Viscum has been employed intravenous [29], intratumoral [30], and also intravenously in pediatric cancer case reports. A recent case series from Essen pediatric oncology reported some benefit in heavily pretreated advanced pediatric cancer patients treated with intravenous Viscum (4/10 patients reported a partial response and 2/10 stable disease), and side effects requested hospitalization [31].

Twelve years after the start of our study, the patients treated with Viscum album fermentatum Pini continue to have a considerably and statistically significant longer PRDFS compared to the oral etoposide arm. Also, side effects and quality of life measured with EORTC QOL30 were favorable to the Viscum arm as previously reported [25]. Viscum can be administrated safely subcutaneously for years without serious side effects, while prolonged use of etoposide can increase the risk of second cancer. This study has the limitation of the small sample size. Patients were oligometastatic mainly to the lungs, so it was a favorable set of patients, but they were well balanced in the two arms, and the differences were significant. The 5-yr PRDSF results $(55.5 \%$ in the Viscum arm) of this small study is better than previously reported $[2,4]$. In fact, if we compare results from another report by Tirtei et al. [4], in which patients with lung metastases only have a 5 -yrs postsecond relapse DFS of $33.6 \%$ and those with one lung nodule only had a 5-yr PRDFS of $42 \%$ lower than the results of our study.

Also, the results of 10-year overall survival forecast are encouraging (64\% for Viscum vs 33\% for etoposide). Those patients who could reach a third complete surgical remission after the third relapse had an improved OS in both arms underling the importance of surgical resection of metastases to reach a longer survival. The analysis of lymphocyte subpopulation changes during time in the two treatment arms, indicating a different lymphocyte distribution between the two treatments, and at 6 months, it was almost opposite $(p<0,05)$ (Figure 3$)$ with an increase of $\mathrm{T}$ subpopulations (CD3, CD4, and NK) in the Viscum arm, while a net decrease is observed in the etoposide arm (Figures 4(a) and 4(b)). Viscum could be used in patients free from disease at high risk of recurrence as maintenance therapy and compared in a randomized trial with other drugs or biologic response modifiers. If we consider that so far cytotoxic maintenance therapy has not proved effective in osteosarcoma, an inexpensive maintenance treatment like Viscum should be encouraged to be further evaluated in postrelapsed osteosarcoma.

So far, the scientific community and pharmaceutical companies showed no interest in randomized trials with Viscum compared to other conventional therapies. We hope that the results of this study will encourage future multicenter, international studies. 


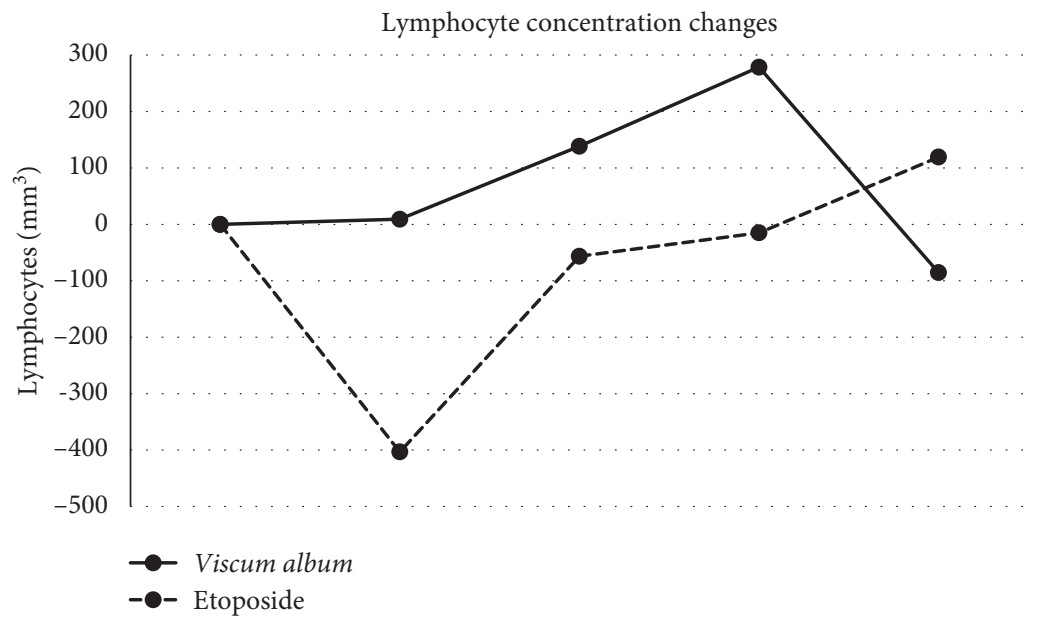

\begin{tabular}{lccccc}
\hline Treatment & Baseline & 3-month delta & 6-month delta & 9-month delta & 12-month delta \\
\hline Viscum album & 0 & $9.14 \pm 240.32$ & $138.43 \pm 518.60$ & $278.60 \pm 429.52$ & $-85.60 \pm 409.01$ \\
& & & & & \\
\hline Etoposide & 0 & $403.25 \pm 249.35$ & $56.500 \pm 392.45$ & $15.000 \pm 169.50$ & $119.250 \pm 248.97$
\end{tabular}

Results are expressed as means \pm standard deviation. Comparison between treatments were performad by Mann-Whitney $U$ test: $p<0.01$ between treatments at 3 month delta.

FIgUre 3: Total Lymphocyte count in Viscum- and Etoposide-treated patients at T0, T3, T6, T9, and T12.

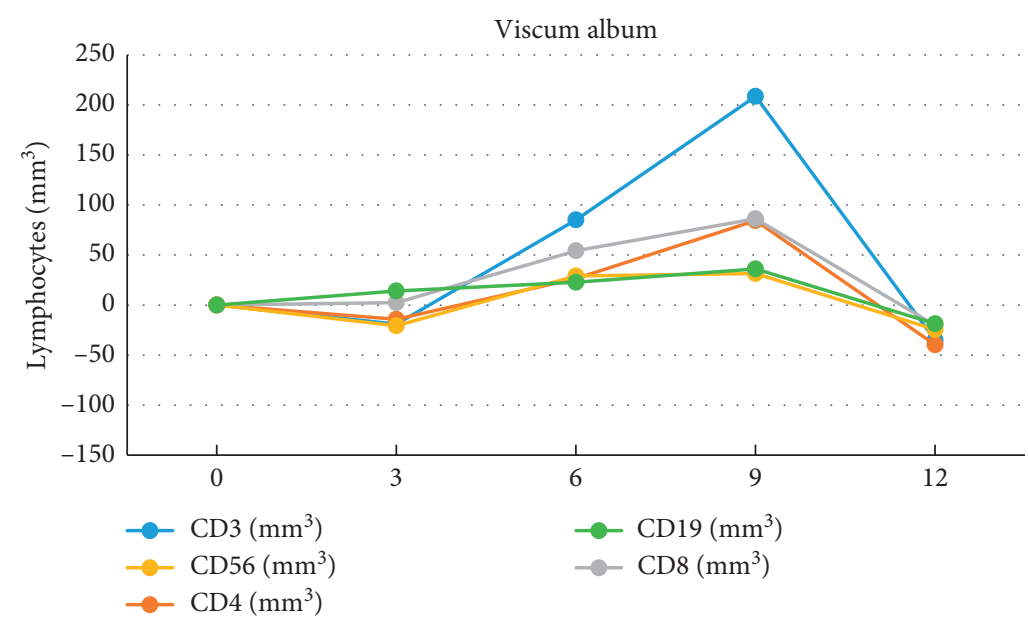

\begin{tabular}{lccccc}
\hline Phenotype & Baseline & 3-month delta & 6-month delta & 9-month delta & 12-month delta \\
\hline CD3 & 0 & $-19.08 \pm 251.16$ & $85.25 \pm 271.96$ & $208.66 \pm 298.28$ & $-35.13 \pm 209.23$ \\
\hline CD4 & 0 & $14.27 \pm 144.53$ & $26.45 \pm 170.78$ & $84.38 \pm 149.58$ & $-39.82 \pm 102.51$ \\
\hline CD8 & 0 & $2.48 \pm 80.14$ & $54.33 \pm 96.95$ & $86.22 \pm 131.97$ & $-20.38 \pm 101.57$ \\
\hline CD56 & 0 & $20.72 \pm 102.48$ & $29.17 \pm 193.47$ & $31.41 \pm 190.36$ & $-24.59 \pm 180.06$ \\
\hline CD19 & 0 & $14.07 \pm 42.64$ & $22.85 \pm 85.37$ & $36.11 \pm 72.69$ & $-18.63 \pm 40.76$ \\
\hline
\end{tabular}

Results are expressed as means \pm standard deviation. Comparison between treatments were performad by Mann-Whitney $U$ test: significant treatments at 3 month delta between treatments for CD56, $p<0.05$ and for CD20. $p<0.001$.

(a)

FIGURE 4: Continued. 


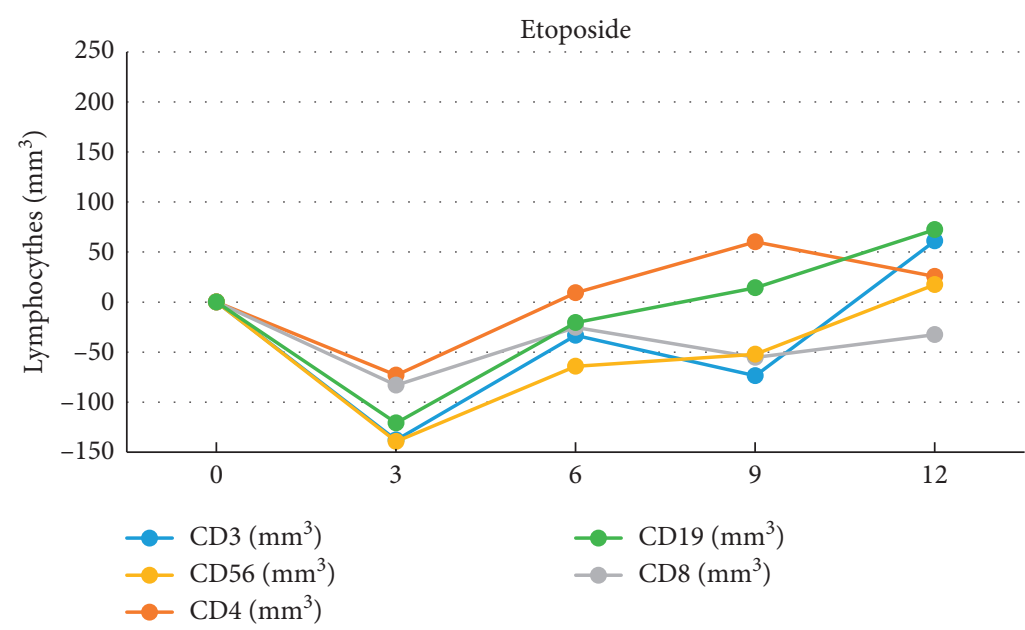

\begin{tabular}{lccccc}
\hline Phenotype & Baseline & 3-month delta & 6-month delta & 9-month delta & 12-month delta \\
\hline CD3 & 0 & $-37.88 \pm 276.81$ & $-33.23 \pm 297.59$ & $-73.60 \pm 263.76$ & $61.09 \pm 167.88$ \\
\hline CD4 & 0 & $-73.17 \pm 116.24$ & $9.30 \pm 179.02$ & $60.17 \pm 30.15$ & $26.62 \pm 121.35$ \\
\hline CD8 & 0 & $-83.18 \pm 162.19$ & $-25.40 \pm 125.45$ & $-55.40 \pm 115.40$ & $-32.52 \pm 102.56$ \\
\hline CD56 & 0 & $-139.40 \pm 128.30$ & $-64.17 \pm 61.27$ & $-52.20 \pm 37.94$ & $17.45 \pm 84.27$ \\
\hline CD19 & 0 & $-120.87 \pm 64.90$ & $-20.61 \pm 106.95$ & $14.31 \pm 29.19$ & $72.34 \pm 87.55$ \\
\hline
\end{tabular}

Results are expressed as means \pm standard deviation. Comparison between treatments were performad by Mann-Whitney $U$ test: significant treatments at 3 month delta between treatments for CD56, $p<0.05$ and for CD20. $p<0.001$.

(b)

FIGURE 4: Lymphocyte subgroup count in (a) Viscum and (b) etoposide.

TABLE 2: Correlation between variations of cell population at different time points.

\begin{tabular}{|c|c|c|c|c|c|c|c|c|c|c|c|c|c|c|c|c|}
\hline & $\begin{array}{l}\text { Lympho } \\
\text { delta3m }\end{array}$ & $\begin{array}{l}\text { Lympho } \\
\text { delta6m }\end{array}$ & $\begin{array}{l}\text { Lympho } \\
\text { delta9m }\end{array}$ & $\begin{array}{l}\text { Lympho } \\
\text { delta } 12 \mathrm{~m} \\
\end{array}$ & \begin{tabular}{|c|}
$\mathrm{CD} 3$ \\
delta3m \\
\end{tabular} & $\begin{array}{c}\mathrm{CD} 3 \\
\text { delta6m }\end{array}$ & $\begin{array}{c}\mathrm{CD} 3 \\
\text { delta9m } \\
\end{array}$ & $\begin{array}{c}\mathrm{CD} 3 \\
\text { delta } 12 \mathrm{~m} \\
\end{array}$ & $\begin{array}{c}\mathrm{CD} 4 \\
\text { delta3m }\end{array}$ & \begin{tabular}{|c|} 
CD4 \\
delta6m \\
\end{tabular} & \begin{tabular}{|c|}
$\mathrm{CD} 4$ \\
delta9m \\
\end{tabular} & $\begin{array}{c}\mathrm{CD} 4 \\
\text { delta12m } \\
\end{array}$ & $\begin{array}{c}\mathrm{CD} 8 \\
\text { delta3m }\end{array}$ & \begin{tabular}{|c|} 
CD8 \\
delta6m \\
\end{tabular} & $\begin{array}{c}\text { CD8 } \\
\text { delta9m }\end{array}$ & $\begin{array}{c}\text { CD8 } \\
\text { delta 2m }\end{array}$ \\
\hline \multicolumn{17}{|l|}{$\mathrm{CD} 3$ delta 3} \\
\hline & & & & & & & & & & & & & & & & \\
\hline \multicolumn{17}{|l|}{ CD3 delta 6} \\
\hline & & & & & & & & & & & & & & & & \\
\hline \multicolumn{17}{|l|}{ CD3 delta 9} \\
\hline & & & & & & & & & & & & & & & & \\
\hline \multicolumn{17}{|l|}{$\mathrm{CD} 3$ delta 12} \\
\hline & & & & & & & & & & & & & & & & \\
\hline \multicolumn{17}{|l|}{$\mathrm{CD} 4$ delta 3} \\
\hline & & & & & & & & & & & & & & & & \\
\hline \multicolumn{17}{|l|}{ CD4 delta 6} \\
\hline & & & & & & & & & & & & & & & & \\
\hline \multicolumn{17}{|l|}{ CD4 delta 9} \\
\hline & & & & & & & & & & & & & & & & \\
\hline \multicolumn{17}{|l|}{ CD4 delta 12} \\
\hline & & & & & & & & & & & & & & & & \\
\hline \multicolumn{17}{|l|}{ CD8 delta 3} \\
\hline & & & & & & & & & & & & & & & & \\
\hline \multicolumn{17}{|l|}{ CD8 delta 6} \\
\hline & & & & & & & & & & & & & & & & \\
\hline \multicolumn{17}{|l|}{ CD8 delta 9} \\
\hline & & & & & & & & & & & & & & & & \\
\hline CD8 delta 12 & & & & & & & & & & & & & & & & \\
\hline & & & & & & & & & & & & & & & & \\
\hline
\end{tabular}

VA is reported in black, and Eto is reported in grey. Correlation was determined by the Pearson correlation test: $p<0.05$ at least for all the colored boxes. 


\section{Data Availability}

Data regarding this study will be available if requested.

\section{Conflicts of Interest}

The authors declare that they have no conflicts of interest.

\section{Acknowledgments}

The authors would like to thank Dr Marcus Reif for his contribution in statistical analysis and Dr. Federica Magagnoli and Dr. Silvia Luppi for their contribution in PgP analysis. They also thank Alba Balladelli for translation. The 2007 study was supported by Iscador AG for Viscum costs and study cost as previously reported.

\section{References}

[1] G. Bacci, A. Briccoli, A. Longhi et al., "Treatment and outcome of recurrent osteosarcoma: experience at Rizzoli in 235 patients initially treated with neoadjuvant chemotherapy," Acta Oncologica, vol. 44, no. 7, pp. 748-755, 2005.

[2] S. S. Bielack, B. Kempf-Bielack, D. Branscheid et al., "Second and subsequent recurrences of osteosarcoma: presentation, treatment, and outcomes of 249 consecutive Cooperative Osteosarcoma Study Group patients," Journal of Clinical Oncology, vol. 27, no. 4, pp. 557-565, 2009.

[3] A. Briccoli, M. Rocca, M. Salone, G. A. Guzzardella, A. Balladelli, and G. Bacci, "High grade osteosarcoma of the extremities metastatic to the lung: long-term results in 323 patients treated combining surgery and chemotherapy, 19852005," Surgical Oncology, vol. 19, no. 4, pp. 193-199, 2010.

[4] E. Tirtei, S. D. Asaftei, R. Manicone et al., "Survival after second and subsequent recurrences in osteosarcoma: a retrospective multicenter analysis," Tumori Journal, vol. 104, no. 3, pp. 202-206, 2018.

[5] C. Steinborn, A. M. Klemd, A.-S. Sanchez-Campillo et al., "Viscum album neutralizes tumor-induced immunosuppression in a human in vitro cell model," PLoS One, vol. 12, no. 7, Article ID e0181553, 2017.

[6] R. M. Webster, "The immune checkpoint inhibitors: where are we now?” Nature Reviews Drug Discovery, vol. 13, no. 12, pp. 883-884, 2014.

[7] W. B. Coley, "Contribution to the knowledge of sarcoma," Annals of Surgery, vol. 14, pp. 199-222, 1891.

[8] S. Miwa, T. Shirai, N. Yamamoto et al., "Current and emerging targets in immunotherapy for osteosarcoma," Journal of Oncology, vol. 20198 pages, 2019, https://doi.org/10. 1155/2019/7035045.

[9] S. S. Bielack, S. Smeland, J. S. Whelan et al., "Methotrexate, doxorubicin, and cisplatin (MAP) plus maintenance pegylated interferon alfa- $2 \mathrm{~b}$ versus MAP alone in patients with resectable high-grade osteosarcoma and good histologic response to preoperative MAP: first results of the EURAMOS-1 good response randomized controlled trial," Journal of Clinical Oncology, vol. 33, no. 20, pp. 2279-2287, 2015.

[10] P. A. Meyers, C. L. Schwartz, M. D. Krailo et al., "Osteosarcoma: the addition of muramyl tripeptide to chemotherapy improves overall survival-A report from the children's oncology group," Journal of Clinical Oncology, vol. 26, no. 4, pp. 633-638, 2008.
[11] K. Boye, A. Longhi, S. Næss et al., "Pembrolizumab in advanced osteosarcoma: results of a single-arm, open-label phase 2 trial," CTOS, 2019.

[12] A. Molassiotis, P. Fernadez-Ortega, D. Pud et al., "Use of complementary and alternative medicine in cancer patients: a European survey," Annals of Oncology, vol. 16, no. 4, pp. 655-663, 2005.

[13] U. Schwabe and D. Paffrath, Arzneiverordnungsreport 2005, Springer-Verlag, Heidelberg, Germany, 2005.

[14] B. N. Singh, C. Saha, D. Galun, D. K. Upreti, J. Bayry, and S. V. Kaveri, "European Viscum album: a potent phytotherapeutic agent with multifarious phytochemicals, pharmacological properties and clinical evidence," RSC Advances, vol. 6, no. 28, pp. 23837-23857, 2016.

[15] S. R. Elluru, J. P. Van Huyen, S. Delignat et al., "Antiangiogenic properties of viscum album extracts are associated with endothelial cytotoxicity," Anticancer, vol. 29, no. 8, pp. 2945-2950, 2009.

[16] S. Kleinsimon, G. Kauczor, S. Jaeger, A. Eggert, G. Seifert, and C. Delebinski, "ViscumTT induces apoptosis and alters IAP expression in osteosarcoma in vitro and has synergistic action when combined with different chemotherapeutic drugs," BMC Complementary and Alternative Medicine, vol. 17, no. 1, p. 26, 2017.

[17] M. Twardziok, S. Kleinsimon, J. Rolff et al., "Multiple active compounds from Viscum album L. synergistically converge to promote apoptosis in Ewing sarcoma," PLoS One, vol. 11, no. 9, Article ID e0159749, 2016.

[18] K. Menke, M. Schwermer, A. Schramm, and T. J. Zuzak, "Preclinical evaluation of antitumoral and cytotoxic properties of viscum album fraxini extract on pediatric tumor cells," Planta Medica, vol. 85, no. 14-15, pp. 1150-1159, 2019.

[19] C. Saha, M. Das, E. Stephen-Victor, A. Friboulet, J. Bayry, and S. V. Kaveri, "Differential effects of viscum album preparations on the maturation and activation of human dendritic cells and $\mathrm{CD}^{+} \mathrm{T}$ cell responses," Molecules, vol. 21, no. 7, p. 912, 2016, https://doi.org/10.3390/molecules21070912.

[20] J. Domont, S. Dumont, A. S. Rahal et al., "Metronomic chemotherapy using oral etoposide in metastatic osteosarcoma," Journal of Clinical Oncology, vol. 34, Article ID e22504,A, 2016 https://doi.org/10.1200/jco.2016.34.15_suppl. e22504.

[21] M.-C. Le Deley, T. Leblanc, A. Shamsaldin et al., "Risk of secondary leukemia after a solid tumor in childhood according to the dose of epipodophyllotoxins and anthracyclines: a case-control study by the société française d'Oncologie pédiatrique," Journal of Clinical Oncology, vol. 21, no. 6, pp. 1074-1081, 2003.

[22] M. Yagita, Y. Ieki, R. Onishi et al., "Therapy-related leukemia and myelodysplasia following oral administration of etoposide for recurrent breast cancer," International Journal of Oncology, vol. 13, no. 13, pp. 91-96, 1998.

[23] T. Kikuta, C. Shimazaki, H. Hirai et al., "Three cases of secondary acute myeloid leukemia after long-term treatment with oral etoposide," Rinsho Ketsueki, vol. 37, no. 11, pp. 1276-1282, 1996.

[24] A. Ng, G. M. Taylor, and O. B. Eden, "Secondary leukemia IN a child with neuroblastoma while ON oral etoposide: what is the Cause?" Pediatric Hematology and Oncology, vol. 17, no. 3, pp. 273-279, 2000.

[25] A. Longhi, M. Reif, E. Mariani, and S. Ferrari, "A randomized study on postrelapse disease-free survival with adjuvant mistletoe versus oral etoposide in osteosarcoma patients," 
Evidence-Based Complementary and Alternative Medicine, vol. 20149 pages, 2014, https://doi.org/10.1155/2014/210198.

[26] M. Serra, K. Scotlandi, G. Reverter-Branchat et al., "Value of P-glycoprotein and clinicopathologic factors as the basis for new treatment strategies in high-grade osteosarcoma of the extremities," Journal of Clinical Oncology, vol. 21, no. 3, pp. 536-542, 2003

[27] A. A. Senerchia, C. R. Macedo, S. Ferman et al., "Results of a randomized, prospective clinical trial evaluating metronomic chemotherapy in nonmetastatic patients with high-grade, operable osteosarcomas of the extremities: a report from the Latin American Group of Osteosarcoma Treatment," Cancer, vol. 123, no. 6, pp. 1003-1010, 2017.

[28] T. Ostermann, C. Raak, and A. Büssing, "Survival of cancer patients treated with mistletoe extract (Iscador): a systematic literature review," BMC Cancer, vol. 9, p. 451, 2009.

[29] P. Schöffski, S. Riggert, P. Fumoleau et al., "Phase I trial of intravenous aviscumine (rViscumin) in patients with solid tumors: a study of the European organization for research and treatment of cancer new drug development group," Annals of Oncology, vol. 15, no. 12, pp. 1816-1824, 2004.

[30] M. L. Steele, J. Axtner, A. Happe, M. Kröz, H. Matthes, and F. Schad, "Use and safety of intratumoral application of European mistletoe (Viscum album L) preparations in Oncology," Integrative Cancer Therapies, vol. 14, no. 2, pp. 140-148, 2015.

[31] T. J. Zuzak, A. Wasmuth, S. Bernitzki, M. Schwermer, and A. Längler, "Safety of high-dose intravenous mistletoe therapy in pediatric cancer patients: a case series," Complementary Therapies in Medicine, vol. 40, pp. 198-202, 2018. 